\title{
Recapitulation of Embryological Programmes in Renal Fibrosis - The Importance of Epithelial Cell Plasticity and Developmental Genes
}

\author{
Sarah A. Roxburgh a, b Madeline Murphy ${ }^{a}$ Carol A. Pollock \\ Derek P. Brazila, b \\ ${ }^{a}$ UCD School of Medicine and Medical Science, UCD Conway Institute, and ${ }^{b}$ Mater Misericordiae \\ University Hospital, University College Dublin, Dublin, Ireland; ${ }^{\mathrm{C}}$ The Kolling Research Institute, \\ Royal North Shore Hospital, University of Sydney, Sydney, Australia
}

\section{Key Words}

Epithelial-mesenchymal transition - Tubulointerstitial fibrosis - Transforming growth factor- $\beta \cdot$ Gremlin •

Diabetic nephropathy $\cdot$ Bone morphogenic proteins

\begin{abstract}
Chronic fibrosis represents the final common pathway in progressive renal disease. Myofibroblasts deposit the constituents of renal scar, thus crippling renal function. It has recently emerged that an important source of these pivotal effector cells is the injured renal epithelium. This review concentrates on the process of epithelial-mesenchymal transition (EMT) and its regulation. The role of the developmental gene, gremlin, which is reactivated in adult renal disease, is the subject of particular focus. This member of the cysteine knot protein superfamily is critical to the process of nephrogenesis but quiescent in normal adult kidney. There is increasing evidence that gremlin expression reactivates in diabetic nephropathy, and in the diseased fibrotic kidney per se. Known to antagonize members of the bone morphogenic protein (BMP) family, gremlin may also act downstream of TGF- $\beta$ in induction of EMT. An increased understanding of the extracellular modulation of EMT and, in particular, of the gremlin-BMP axis may result in strategies that can halt or reverse the devastating progression of chronic renal fibrosis.
\end{abstract}

Copyright @ 2006 S. Karger AG, Basel

KARGER
Fax +41 61306 1234
E-Mail karger@karger.ch
www.karger.com (c) 2006 S. Karger AG, Basel $1660-2137 / 06 / 1033-0139 \$ 23.50 / 0$

Accessible online at:

www.karger.com/nep

\section{Introduction}

Chronic kidney disease (CKD) imposes an enormous burden on society. Progression of CKD is irreversible, culminating in end stage renal failure (ESRF). Effective strategies slow the rate of progression of CKD but therapies to halt or reverse the process are currently absent. ESRF is a devastating diagnosis, both in human and health economic terms, currently managed by dialysis or transplantation. These strategies of renal replacement therapy (RRT) account for a large proportion of any developed world health care budget, yet unfortunately, the number of ESRF patients on RRT is increasing at a significant rate [1]. This can largely be ascribed to a dramatic rise in both incidence and prevalence of diabetic nephropathy (DN) in both the developed and developing world. This trend is most pronounced in the United States and is illustrated by 2004 US Renal Data Sytem data. In 1980, DN was listed as the primary aetiology underlying ESRF in $20 \%$ of the prevalent population; by 2004, it was the underlying diagnosis in $45 \%$ of the prevalent population. The growing prevalence reflects both increasing incidence and longer patient survival [2].

Chronic progressive fibrosis is the "final common pathway' to ESRF through which a variety of progressive renal diseases, including DN, advance. Scarred kidneys classically display the triad of glomerulosclerosis, interstitial fibrosis and tubular atrophy. Rather than histopathologic

Dr. Derek P. Brazil

UCD Conway Institute

University College Dublin

Belfield, Dublin 4 (Ireland)

Tel. +35317166819, Fax +35317166701, E-Mail derek.brazil@ucd.ie 
changes at the level of the glomerulus, it is the development of tubulointerstitial fibrosis (TIF) in primary glomerular disease that most closely correlates with rate of progression of chronic renal dysfunction. Irrespective of primary aetiology, TIF, once established, appears to follow a uniform, predictable course [3].

Recently, the concept of phenotypic plasticity of the renal tubular epithelial cell (TEC) has been established. This unique ability allows the injured epithelial cell to convert to a fibroblastic phenotype, capable of migration into the tubulointerstitium and thus of contribution to fibrogenesis $[4,5]$. Delineation of the molecular mechanisms of this 'reversed embryogenesis' [4], or epithelialmesenchymal transition (EMT), creates exciting new possibilities for the discovery of both novel disease biomarkers and therapeutic targets. This review will address current concepts of the molecular mechanisms of EMT, with particular focus on the recapitulation of developmental genes such as gremlin in the adult disease state.

\section{EMT}

Characteristic features of renal fibrosis include an atrophied tubular architecture and an accumulating extracellular matrix (ECM) that relentlessly deposits and expands the interstitial space [6]. Interstitial myofibroblasts are the primary effector cells in this process and their accumulation has been demonstrated to predict disease progression in many forms of CKD, including DN [7, 8]. Originally postulated to be either locally activated renal fibroblasts that migrate into the tubulointerstitium or bone-marrow-derived mesenchymal precursor cells, seminal work from Strutz et al. [9] suggested that TECs can transition to fibroblastic phenotype via EMT.

The concept of epithelial cell plasticity is central to organogenesis and more specifically, to renal embryology. The mammalian kidney derives from two distinct origins. The collecting system stems from epithelial wolffian duct, but the majority of adult renal epithelia (that is, from glomerulus to the beginning of collecting tubule) originates from metanephric mesenchyme. This latter group derives via the process of mesenchymal to epithelial transition (MET).This essential capacity of epithelial and mesenchymal cells to interconvert during development ensures that cells can acquire migratory capacity and thus traverse the extracellular environment, ultimately settling in distinct areas to form organs [10]. Conversely, in adult tissue, mesenchymal and epithelial cells have traditionally been considered as terminally differentiated.
It is postulated that EMT occurs in differentiated adult renal epithelium when the tubular cell responds to injury by losing its epithelial phenotype and acquiring the characteristic features of mesenchyme. EMT may thus allow epithelial cells to escape from an apoptotic fate [11] and enable migration into the tubulointerstitium. An additional pool of matrix-producing fibroblasts is thus created. Although this cell population can effect repair of injured tissue, it is proposed that this situation is maladaptive and favours fibrogenesis [5]. Thus, EMT is a process in which the programmes of renal embryology are reversed, allowing cell dedifferentiation back to original embryological mesenchymal phenotype. It is important to note that evidence to date has only observed EMT occurring in those kidney cells with lineage originally of MET derivation $[4,5]$. Almost all in vitro studies that document EMT have employed proximal tubular cells as a model system. However there is recent evidence that distal tubular cells also undergo EMT in response to injury [12] and that glomerular parietal epithelial cells undergo EMT in in vivo models of CKD [13]. This makes intuitive sense as glomerular epithelial cells and distal tubular cells derive from the same embryonic mesenchymal origin. Conversely, there is evidence that collecting duct epithelium does not undergo phenotypic change on exposure to the multifunctional growth factor, TGF- $\beta 1$, consistent with the fact that it is of differing embryological origin [14].

EMT is characterized by a number of defined cellular changes. Initially, a transition in morphology from the cobblestone-like cell sheet typical of an epithelial phenotype to the elongated, fusiform cell sheet characteristic of fibroblasts occurs. The epithelial cells lose polarity and cell-cell adhesion and gain mesenchymal properties including motility. Secondly, a loss of epithelial markers (e-cadherin, cytokeratin, ZO-1) is demonstrated. A corresponding increase in mesenchymal markers such as vimentin, $\alpha$-SMA and/or fibroblast-specific protein-1 (FSP-1) also occurs [15].

\section{EMT in Renal Fibrosis}

Murine FSP-1, an S100-binding protein, was identified as a mesenchymal marker in a landmark study suggesting phenotypic conversion of the TEC [9]. Some TECs were noted to become FSP-1 positive in murine models of CKD $[16,17]$. Thus a new hypothesis was generated; EMT serves as a potential source of fibroblasts in the fibrotic kidney. Okada et al. [15] evaluated the effects 
of various cytokines on murine TECs in vitro, demonstrating that the combination of transforming growth factor- $\beta 1$ (TGF- $\beta 1$ ) and epidermal growth factor (EGF) was most efficacious in inducing EMT. Evidence of EMT was subsequently demonstrated in a number of other animal models of CKD [14, 18]. Significant evidence for EMT in human disease has been demonstrated; in 133 human renal biopsies, the number of tubular cells demonstrating evidence of EMT clearly correlated with both serum creatinine and the degree of TIF [19]. Tubular EMT is also relevant in experimental and human $\mathrm{DN}$; there is evidence that this is mediated by an advanced glycation endproduct (AGE)-receptor for advanced glycation endproduct (RAGE) interaction and thus may play a critical role in DN pathogenesis [20].

Pivotal work by Iwano et al. [21] allowed the quantitative, unambiguous identification of those renal fibroblasts in the interstitial pool that originally derived from tubular epithelium. These authors demonstrated that genetically tagged proximal TECs in transgenic mice exhibited a degenerate morphology, became disorganized and migrated into the interstitium. The ability to track the precise fate and movement of these cells enabled these authors to demonstrate that over one third of the fibroblast pool were of epithelial origin. These results established the very significant contribution of EMT to renal fibrosis [21]. Supportive evidence was provided by an in vivo model in which selective blockade of EMT was performed. Mice lacking tissue plasminogen activator (tPA) demonstrated blocked tubular EMT but no effect on local interstitial fibroblast activation. In the absence of EMT, progression of myofibroblast accumulation was blunted, and the kidneys were protected from the development of interstitial fibrosis after sustained ureteral obstruction. This study confirmed a definite role for EMT in the pathogenesis of renal interstitial fibrosis in the whole animal [22].

\section{Mechanisms and Models of Tubular EMT}

A cellular model of EMT has been constructed by Yang and Liu [23], primarily based on data from in vitro experiments. Four pivotal events occur during EMT in a highly regulated fashion: firstly, loss of epithelial adhesion; secondly, de novo expression of mesenchymal markers such as $\alpha$-SMA, and cytoskeletal reorganization; thirdly, tubular basement membrane disruption and finally, acquisition of migratory and invasive capacity by the transformed cell.

Embryological Programmes in Renal Fibrosis
There are several known inducers of EMT, including TGF- $\beta 1$ [24], connective-tissue growth factor (CTGF) [25], EGF [15], fibroblast growth factor-2 [26], AGEs [20], angiotensin II [27], interleukin-1 [28], matrix metalloproteinase-2 [29], and type I collagen [15]. Chief amongst this growing list of regulators is the profibrotic cytokine TGF- $\beta 1$, now well recognized as a major effector in the initiation and progression of renal disease. TGF- $\beta 1$ signalling pathways can initiate and drive to completion the entire EMT process in the renal tubular cell in vitro [24]. This growth factor may be the common downstream effector that mediates the actions of some or all of the other factors that induce EMT [4]. Multiple intracellular signalling pathways are involved in EMT. In brief, the Smad pathway, Rho A, mitogen-activated protein kinases, extracellular regulated protein kinases (ERK) and c-Jun N-terminal kinases are involved in TGF- $\beta 1$ induced EMT [30-34].Of note, recent work has indicated that TGF- $\beta 1$ induces generation of cellular reactive oxygen species (ROS) and that these mediate EMT in renal tubular epithelial cells directly through activation of mitogen-activated protein kinases and indirectly through ERK-directed Smad-2 phosphorylation [35].

The increasing body of evidence that supports the concept of epithelial cell plasticity has enhanced understanding of the complex molecular pathways of EMT. One way in which this has been achieved is through large-scale transcriptomic analysis. Recent work from our group compared the transcriptomes of in vitro (tubular EMT) and in vivo (adriamycin nephropathy) models of tubular fibrosis; an example of one gene particularly identified was claudin-1, which appears to play an integral role in the structural integrity of the tubular epithelium [36].

\section{Mediators of EMT - The Bone Morphogenic Proteins}

Bone morphogenic proteins (BMPs) are secreted proteins forming a subgroup within the TGF- $\beta$ superfamily of cysteine-knot cytokines. The group, containing over 30 members, was originally described for their ability to induce the formation of ectopic bone and cartilage in vivo. The BMPs, and particularly BMPs- $2,-4$ and -7 , are known to play an important role in renal development [37-39].

The effects of BMP-7, like the other members of this family, antagonize TGF- $\beta /$ Smad-dependent signalling in renal TECs. BMP-7 appears to have a unique role in nephrogenesis and, particularly, in the modulation of MET [40]. BMP-7 is a survival factor for the metanephric 
mesenchyme and BMP-7 knockout mice exhibit severe renal dysgeneses and die shortly after birth from renal failure [37].

BMP-7 in the adult is primarily expressed in the kidney, and particularly localizes to TECs and glomerular epithelial cells. It appears integral to the maintenance of a differentiated renal epithelial cell phenotype [40]. The robust expression of BMP-7 in normal kidney is, however, dramatically reduced in the diseased, fibrotic kidney, and specifically in in vivo models of DN [41]. Thus, expression of BMP-7 opposes that of TGF- $\beta 1$, which increases in acute and chronic renal disease. It has now been demonstrated that exogenous BMP-7 attenuates progressive loss of renal function and renal fibrosis, reducing injury in in vivo models including obstructive nephropathy, tubulointerstitial nephritis, lupus nephritis and DN [42-44].

Attaining a precise understanding of the mechanisms by which BMP-7 achieves its renoprotective function is thus of high priority. BMP-7 has been shown to reduce the release of proinflammatory cytokines [45]. In the renal mesangial cell, BMP-7 counters the proinflammatory effects of TGF- $\beta 1$ [46]. In TECs, an in vitro model demonstrated that BMP-7 reversed EMT by directly counteracting TGF- $\beta 1$-induced signalling [12]. Zeisberg et al. [47] recently reported that BMP-7 induced some phenotypic changes consistent with MET in adult fibroblasts (reacquisition of e-cadherin and reduced motility). In addition, they reported detection of a novel interstitial cell population co-expressing FSP-1 and e-cadherin in an in vivo mouse model of chronic fibrosis treated with recombinant BMP-7. Thus, the interesting possibility arises that adult fibroblasts may also retain plasticity and thus potentially contribute to healthy epithelial cells in repaired renal tubular structures.

The ability of BMP-7 to reduce inflammatory mediator production, coupled with the potential to reverse TIF, is clearly crucial for maintenance of the structural and functional integrity of the tubular epithelium. BMP-7 appears to counteract endogenous mediated TGF- $\beta 1$ action [48]. Antagonism of the effects of BMP-7 will clearly have deleterious effects, disrupting renal homeostasis and tipping the balance towards progressive inflammation and fibrosis.

\section{Gremlin: A Model for the Reactivation of Developmental Genes in Diabetic Nephropathy and Tubulointerstitial Fibrosis}

Gremlin is a highly conserved, secreted protein that fulfils a pivotal function in diverse processes of growth, differentiation and development, in many cases by antagonizing the activity of BMPs [49]. Gremlin is a cysteine knot protein that can heterodimerize with specific BMPs, thus preventing their interactions with TGF- $\beta$ receptors. Other members of this cysteine knot superfamily include the tumour suppressor DAN and the head-inducing factor Cerberus [50]. Originally identified as a dorsalizing factor in Xenopus laevis, gremlin appears to favour antagonism of BMP-2, -4 and -7 [51, 52]. Gremlin is preferentially expressed in fibroblasts and appears to play a role in cell cycle arrest; overexpression in rat and mouse cell lines leads to growth inhibition and cell cycle arrest [53].

Gremlin is a key regulator of BMP activity in embryonic development and is known to be the principal BMP antagonist that modulates early limb outgrowth and patterning in the mouse embryo [54]. A primary role for gremlin in nephrogenesis is reinforced by the observation that ablation of gremlin expression causes death in homozygous mice within $48 \mathrm{~h}$ of birth due to complete renal agenesis [54, 55]. As previously mentioned, the targets of gremlin binding, BMP-2, -4 and -7 , also have essential functions in renal development.

Recent work has established that gremlin mediates its action via induction of epithelial to mesenchymal feedback signalling. Metanephric renal (and limb bud) organogenesis occurs via BMP antagonism and thus gremlin is confirmed as the essential extracellular signal which initiates renal development [55].

In 1999, our group employed suppression subtractive hybridization to identify 15 genes differentially induced when human mesangial cells were treated with elevated ambient glucose [56].This group includes two novel development genes. One of these was 'Induced in High Glucose' (IHG)-2, later identified via cloning in silico as the developmental gene, gremlin [57]. This key discovery generated the hypothesis that reactivation of developmental genes may occur in adult kidney disease, and specifically, that gremlin may play a role in the pathogenesis of DN. In vitro models of DN were utilized to validate the discovery of this pivotal gene. Elevated levels of gremlin were observed in extracts from model systems such as kidney mesangial cells treated with high glucose, or exposed to cyclical mechanical strain (a model of the glo- 
merular hypertension of diabetes). TGF- $\beta 1$ was shown to induce gremlin expression in human mesangial cells in vitro, while the stimulatory effect of high glucose on gremlin expression was attenuated by the addition of antiTGF- $\beta 1$ antibody [57].

In vivo models provided evidence to support the initial hypothesis. Elevated levels of gremlin were observed in glomeruli micro-dissected from kidneys of the streptozotocin STZ-induced diabetic rat model [57]. Increased levels of gremlin expression correlated with a marked decrease in tubular BMP-7 expression early in experimental DN [41]. Thus, it is possible that gremlin acts downstream of TGF- $\beta 1$ to downregulate BMP-7. Supportive evidence for this was seen in the Goto-Kakizaki rat model of non-obese type II diabetic rats which, at 9-10 months, demonstrated some phenotypic evidence consistent with EMT; tubular e-cadherin was lost and $\alpha$-SMA upregulated on immunocytochemistry of renal tissue. Quantitative PCR results included significant increases in gremlin, TGF- $\beta 1$ and CTGF mRNA in renal extracts from the rats at 9-10 months [58]. These findings coincided with histological changes consistent with moderate DN and TIF [58]. The 5/6 nephrectomy model of glomerular hypertension also demonstrated increased gremlin expression in kidney tissue, thus suggesting a more global role in renal fibrosis [59].

Recent work from our group has pointed to a role for gremlin in the pathogenesis of TIF. Preliminary work with TECs indicated that TGF- $\beta 1$ induced gremlin expression [59]. The first evidence of increased expression of gremlin in human CKD was then demonstrated. Diagnostic kidney biopsies were obtained from the European Renal Complementary DNA Bank, and gremlin expression and localization compared between normal control and tissues with primary aetiologies including DN, rapidly progressive glomerulonephritis, IgA nephropathy and minimal change disease. Gremlin expression was found to be undetectable in normal adult kidney; however, there was a significant increase in gremlin expression in the $10 \mathrm{DN}$ biopsies studied. In situ hybridization demonstrated marked gremlin expression which correlated with more advanced disease. There was clear gremlin localization, primarily to the tubular compartment, and a positive correlation with fibrosis severity and elevations in serum creatinine. Importantly, gremlin expression was found to co-localize with TGF- $\beta 1$ expression, supporting the hypothesis that TGF- $\beta 1$ modulates gremlin expression in the tubulointerstitial compartment. Quantitative studies with real time PCR were performed; gremlin mRNA was found to be significantly elevated in the DN biopsies compared to normal control (2.6 fold; $\mathrm{p}<0.01)$. Again, a direct correlation was seen between serum creatinine and TIF score. A significant increase in gremlin expression was also seen in the rapidly progressive glomerulonephritis group [60].

It thus appears that gremlin is an embryologically expressed gene critical to the regulation of renal morphogenesis that becomes quiescent after birth. This developmental gene may be reactivated in the adult diseased kidney, with the re-emergence being linked to an attempted tissue repair that becomes maladaptive [50]. The high abundance of gremlin in the tubular compartment in advanced $\mathrm{DN}$ and its correlation with fibrosis severity and creatinine points to an important role for gremlin in the pathogenesis of TIF. Co-localization with TGF- $\beta 1$ points to this profibrotic cytokine having a role in the modulation of gremlin in the tubular compartment, as it does in the glomerular compartment. As a secreted modulator of TGF- $\beta 1$ signalling, gremlin may be an attractive option as a diagnostic marker and possibly as a target for antifibrotic therapy.

Table 1 summarizes the roles of BMP-7, gremlin and TGF- $\beta 1$ in renal embryology, normal adult kidney and diseased adult kidney. Figure 1 is a schematic outlining the proposed extracellular modulation of EMT by TGF- $\beta$, gremlin and BMP-7.

\section{EMT and Potential Therapeutic Targets}

The fate of the tubular epithelial cell that has undergone EMT in response to injury is fascinating. Potentially, the transformed cell may proliferate to expand the fibroblast population, undergo apoptosis, or revert back to epithelial type [4]. This last possibility offers exciting potential for therapeutic development - if on exposure to regenerative cues the cell is able to redifferentiate back to epithelial form, and then it would appear possible to reverse renal fibrosis.

A significant role for modulation of EMT by exogenous agents has been described. Angiotensin II potentiates EMT and its inhibition leads to reduced renal fibrosis [27]. ROCK, a downstream effector kinase of RhoA that plays an important role in cytoskeletal disassembly in EMT, can be inhibited by Y-27632, a ROCK antagonist. This agent attenuates fibrosis in a murine model of obstructive nephropathy [67]. Experiments using ROS suggest that antioxidants and mitogen-activated protein kinase inhibitors may have a role in antagonism of EMT [35]. It has been demonstrated that the AGE-RAGE path- 
Table 1. Summary of current data for gremlin, BMP-7 and TGF- $\beta$ in renal development and disease

\begin{tabular}{|c|c|c|c|}
\hline & Gremlin & BMP-7 & TGF- $\beta$ \\
\hline General & $\begin{array}{l}\text { - member of cysteine knot superfamily } \\
\text { secreted peptide } \\
\text { - heterodimerizes with BMPs; prevents } \\
\text { interaction with serine/threonine kinase } \\
\text { receptors } \\
\text { - roles in growth, differentiation and } \\
\text { development }\end{array}$ & $\begin{array}{l}\text { - member of TGF- } \beta \text { superfamily } \\
\text { - secreted peptide } \\
\text { - activates serine/threonine kinase } \\
\text { receptors } \\
\text { - diverse roles in growth and } \\
\text { development }\end{array}$ & $\begin{array}{l}\text { - member of TGF- } \beta \text { superfamily } \\
\text { - secreted peptide, } 3 \text { isoforms } \\
\text { - ligand-induced activation of heteromeric } \\
\text { transmembrane serine/threonine receptor } \\
\text { kinases } \\
\text { - multifunctional; regulates cell } \\
\text { proliferation, differentiation, apoptosis, } \\
\text { immune response and ECM remodelling }\end{array}$ \\
\hline Renal organogenesis & $\begin{array}{l}\text { - principle BMP antagonist modulating } \\
\text { renal development [46] } \\
\text { - in knockout mice, complete renal } \\
\text { agenesis }[46,47]\end{array}$ & $\begin{array}{l}\text { - mediates branching morphogenesis \& } \\
\text { modulates MET [33] } \\
\text { - in knockout mice, severe renal } \\
\text { dysgenesis [30] }\end{array}$ & $\begin{array}{l}\text { - inhibits branching morphogenesis in } \\
\text { kidney [6] } \\
\text { - loss of TGF- } \beta 2 \text { leads to renal agenesis in } \\
\text { female mice [61] }\end{array}$ \\
\hline \multicolumn{4}{|l|}{ Diabetic nephropathy } \\
\hline i) in vitro & $\begin{array}{l}\text { - induced in mesangial cells } \\
\text { high glucose [48] } \\
\text { TGF- } \beta 1 \text { [49] } \\
\text { cyclical mech. strain [49] }\end{array}$ & - nil to date & $\begin{array}{l}\text { - high ambient glucose upregulates } \\
\text { expression and bioactivity of TGF } \beta \text { in } \\
\text { mesangial, tubular and almost all other } \\
\text { renal cell types [62-64] }\end{array}$ \\
\hline ii) in vivo & $\begin{array}{l}\text { - elevated levels renal tissue } \\
\text { STZ rat model }[34,49] \\
\text { GK rat model }[50]\end{array}$ & $\begin{array}{l}\text { - dramatic reduction in renal expression } \\
\text { in STZ rat model [34] }\end{array}$ & $\begin{array}{l}\text { - overexpression of TGF- } \beta \text { in both } \\
\text { glomerular and tubulointerstitial } \\
\text { compartments of diabetic animals }[65,66]\end{array}$ \\
\hline & & $\begin{array}{l}\text { - exogenous recombinant BMP } 7 \\
\text { attenuates progession DN [36] }\end{array}$ & \\
\hline iii) human & $\begin{array}{l}\text { - Elevated levels in human DN biopsies } \\
\text { [52] }\end{array}$ & - nil to date & - correlates with disease progression [67] \\
\hline \multicolumn{4}{|c|}{ Tubulointerstitial fibrosis } \\
\hline i) in vitro & $\begin{array}{l}\text { - TGF- } \beta 1 \text { induces gremlin expression in } \\
\text { tubular cells }[51]\end{array}$ & $\begin{array}{l}\text { - counteracts TGF- } \beta \text { in renal mesangial } \\
\text { and tubular cells }[12,39] \\
\text { - reduces release proinflammatory } \\
\text { cytokines at level tubular cell }[38] \\
\text { - induces some changes consistent with } \\
\text { MET in renal fibroblast }[40]\end{array}$ & $\begin{array}{l}\text { - primary inducer of EMT; can initiate } \\
\text { entire course in isolation [23] } \\
\text { - secreted by the tubular cell as undergoes } \\
\text { EMT; autocrine loop [6] }\end{array}$ \\
\hline ii) in vivo & - nil to date & $\begin{array}{l}\text { - attenuates progressive fibrosis in } \\
\text { multiple rodent models }[35,37]\end{array}$ & $\begin{array}{l}\text { - increased expression associated with } \\
\text { progression of renal fibrosis [68] }\end{array}$ \\
\hline iii) human & $\begin{array}{l}\text { - Colocalizes with TGF- } \beta \text { in tubulo- } \\
\text { interstitial compartment in DN [52] }\end{array}$ & - nil to date & $\begin{array}{l}\text { - localizes to tubulointerstitial } \\
\text { compartment and correlates with fibrosis } \\
\text { severity [52] }\end{array}$ \\
\hline & - increased expression in RPGN [52] & & \\
\hline \multirow[t]{5}{*}{ Summary } & - induced by TGF- $\beta 1$ & $\begin{array}{l}\text {-expression in normal \& diseased } \\
\text { kidney inversely proportional to TGF- } \beta\end{array}$ & $\begin{array}{l}\text { - multifunctional cytokine with pivotal role } \\
\text { in EMT and renal fibrosis }\end{array}$ \\
\hline & $\begin{array}{l}\text { - antagonises BMPs } \\
\text { - pivotal role in modulating renal } \\
\text { organo-genesis }\end{array}$ & $\begin{array}{l}\text { - pivotal role in renal organogenesis } \\
\text { - highly expressed in normal adult } \\
\text { kidney }\end{array}$ & $\begin{array}{l}\text { - induces gremlin } \\
\text { - inhibits BMP } 7 \text { in vitro }\end{array}$ \\
\hline & - not expressed in normal kidney & - lost in fibrosis & $\begin{array}{l}\text { - increasing expression in acute and } \\
\text { chronic renal disease, and specifically in } \\
\text { DN }\end{array}$ \\
\hline & $\begin{array}{l}\text { - recapitulated in adult renal disease, } \\
\text { with highest expression in tubular } \\
\text { compartment }\end{array}$ & $\begin{array}{l}\text { - exogenous administration ameliorates } \\
\text { fibrosis }\end{array}$ & $\begin{array}{l}\text { - plieotropic effects mean not an attractive } \\
\text { therapeutic target }\end{array}$ \\
\hline & & $\begin{array}{l}\text { - key role in maintenance normal tubule } \\
\text { homeostasis }\end{array}$ & \\
\hline
\end{tabular}

way is critical for the pathogenesis of diabetic complications. It now appears that AGEs play an important role in the development of renal fibrosis in a non-diabetic context. AGEs have been shown to be capable of EMT induc- tion in the absence of exogenous TGF- $\beta 1$ [20]. Blockade of the AGE-RAGE interaction and RAGE-activated ERK-1/2 signalling resulted in a complete inhibition of tubular EMT; thus, blockade of these pathways point to 


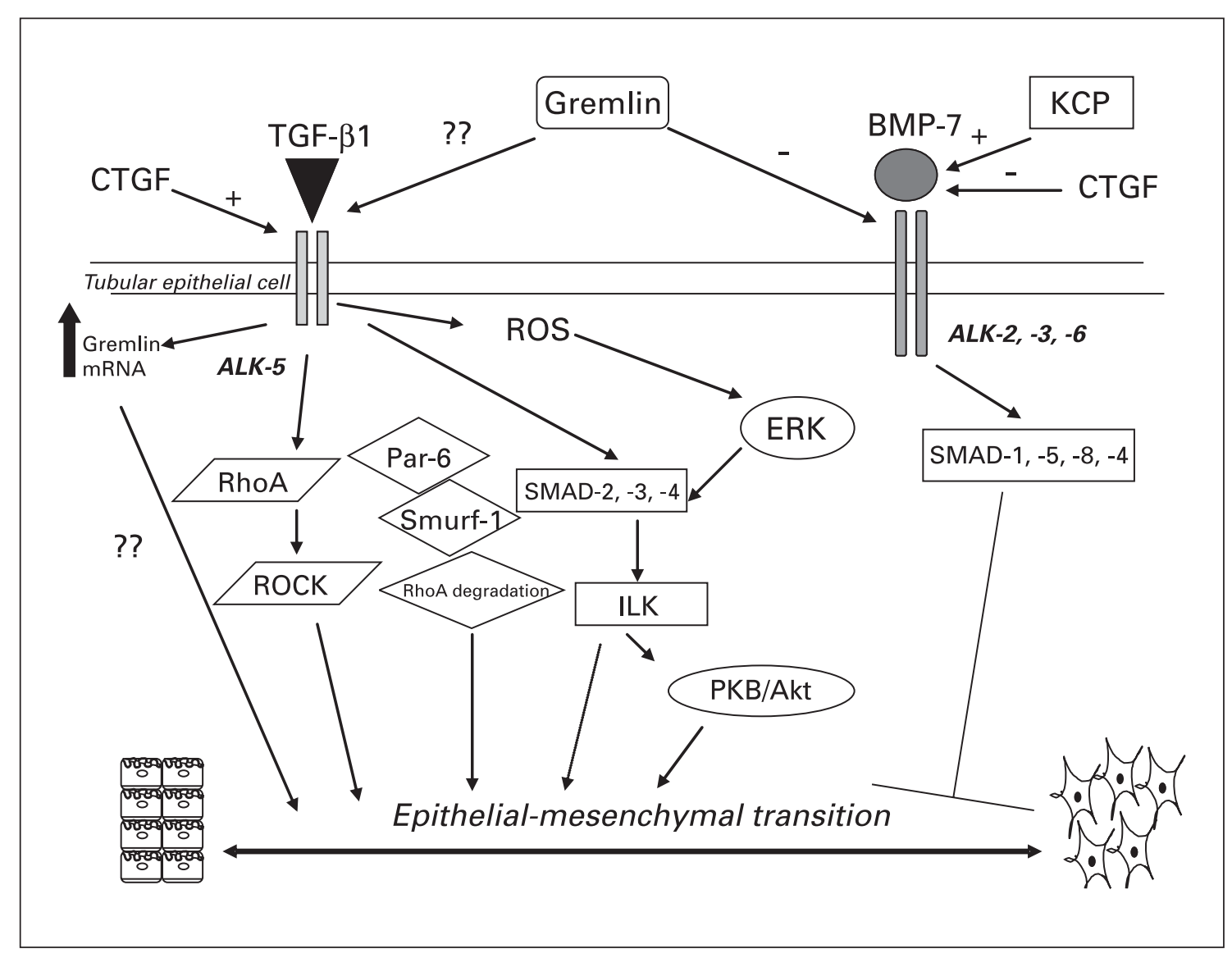

Fig. 1. Overview of the epithelial-mesenchymal transition as modulated by TGF- $\beta$, BMP-7 and gremlin. Free TGF- $\beta$ and BMP-7 are bidirectionally regulated in receptor binding by positive or negative proteins in the extracellular space [61]. CTGF binds TGF- $\beta 1$ and enhances TGF- $\beta$ binding to its extracellular receptor [62]. It is hypothesized that gremlin may also enhance TGF- $\beta$ receptor binding. In addition, we have demonstrated that levels of gremlin mRNA are upregulated in an in vitro model of TGF- $\beta$-induced EMT, thus suggesting that gremlin may act downstream of TGF- $\beta[59,63]$. Gremlin (like the other BMP antagonists noggin, follistatin and chordin) heterodimerizes with BMPs in the extracellular space and prevents them binding to BMP receptors [52]. CTGF has been shown to bind directly to BMP-2 and -4 and to inhibit interaction with the receptor [62]; CTGF is proposed to also have an inhibitory effect on BMP-7. Kielin/chordin-like protein (KCP)-1 is newly documented as a novel enhancer of BMP-7 binding [64].

Activation of the BMP-7 receptor induces phosphorylation of Smad-1, -5 and -8, which opposes epithelial-mesenchymal transition (EMT) in the nucleus [5].

new therapeutic strategies [68]. Administration of an AGE cross-link breaker (ALT-711) reduced evidence of EMT in diabetic rats in association with reduced tubular AGE and TGF- $\beta$ expression [20]. Strutz et al. [69] have identified several myofibroblast inhibitors, including the
Activation of the TGF- $\beta$ receptor induces phosphorylation of Smad-2 and -3 and its nuclear import of Smad-4, resulting in transcriptional activation driving EMT [5]. Downstream kinases such as integrin-linked kinase (ILK) and PKB/Akt phosphorylate targets that mediate EMT progression [65]. Activation of the TGF- $\beta$ receptor also results in activation of a number of other intracellular signalling mechanisms that promote EMT. These include: activation of Rho A which induces ROCK [31]; activation of ROS which induce ERK-directed activation of the Smad pathway [35], and the recently demonstrated regulation of the polarity protein Par-6.The phosphorylation of Par-6 results in Smurf-1 interaction, which targets RhoA for degradation, resulting in loss of tight junctions and ultimately EMT [66].

Thus TGF- $\beta 1$ and gremlin promote EMT, and BMP-7 inhibits EMT. The transitioning epithelia change into myofibroblasts by rearrangement of their actin cytoskeleton and expression of new proteins such as interstitial collagens, matrix metalloproteinases- 2 and -9 , and FSP-1 [4, 5]. Pharmacologic strategies that act to inhibit gremlin, a BMP antagonist, may thus inhibit EMT.

methyl-xanthines, pentoxifylline and pentifylline, which robustly prevented fibroblast formation and proliferation per se as well as ECM formation [69].

Endogenous antagonists of EMT should have limited toxicity and thus possess attractive therapeutic potential. 
Exciting recent work has identified two endogenous antagonists of EMT both in vivo and in vitro; BMP-7 and hepatocyte growth factor (HGF) $[12,14]$. Both of these factors, which appear to be inherently renoprotective, play a substantial role in embryonic nephrogenesis and in maintenance of adult kidney tubular epithelial cell homeostasis [4].

As detailed earlier in this review, recombinant human BMP-7 has resulted in significant renal recovery (in terms of both function and histology) in different rodent models of chronic renal injury in mice and rats [12, 42-44]. Importantly, in both the in vivo models of DN and unilateral urethral obstruction, the recovery of renal function seen with BMP-7 was greater than the benefit obtained from ACE inhibition [43, 44].

Important recent work by Lin et al. [64] has demonstrated that the novel protein kielin/chordin-like protein (KCP), acts as a BMP enhancer. This action is likely to attenuate renal fibrosis as KCP-null mice are more susceptible to the development of renal fibrosis in models of acute tubular necrosis and unilateral urethral obstruction. KCP is expressed in embryonic tissue but not in the normal adult. It appears to be reactivated in response to stress and to be involved in the regulation of renal fibrosis, acting as a potentiator of BMP signalling in a paracrine-like manner.

Liu et al. [70] have established that in a rat remnant kidney model, antagonism of HGF signalling with neutralizing antibody led to marked induction of renal tubular expression of the mesenchymal marker, $\alpha$-SMA. In vitro studies subsequently demonstrated that HGF blocks TGF- $\beta 1$-induced EMT, reversing the phenotypic conversion [14]. Further work in a unilateral urethral obstruction animal model illustrated that administration of HGF protein or gene blocks EMT and attenuates TIF [27].

Recent data on gremlin highlights that there may also be a potential therapeutic role for the modulation of this BMP antagonist and this offers an exciting avenue for future research.

\section{Conclusions}

Tubular fibrosis, the 'final common pathway' in many forms of progressive glomerular disease, closely correlates with the inexorable decline towards ESRF and requirement for RRT. EMT is now established as an important pathway that generates myofibroblasts, the pivotal effector cells in the diseased tubulointerstitium. This epithelial cell plasticity, so important in normal organogenesis, is likely to represent one possible response of the tubular epithelial cell confronted by sustained injury [5].The transformed TEC has the potential to support tissue repair but unfortunately, the recapitulation of this developmental programme in the setting of the adult disease state appears to be maladaptive and the balance is tipped towards fibrogenesis. However, the unique ability of the cell to transition from epithelial to mesenchymal phenotype highlights an exciting area for potential therapeutic manipulation. As increasing evidence points to the cells ability to redifferentiate back to epithelial type with the appropriate regenerative cue, our need to precisely understand the complex mechanisms regulating EMT intensifies. One way in which this can be achieved is through large scale transcriptomic analysis. Recent work from our group compared the transcriptomes of in vitro (tubular EMT) and in vivo (adriamycin nephropathy) models of tubular fibrosis; an example of one gene particularly identified was claudin-1, which appears to play an integral role in the structural integrity of the tubular epithelium [36]. The discovery of gremlin as a potential player in the pathogenesis of DN was made through earlier techniques used to analyze the diseased renal transcriptome. Gremlin, a developmental gene pivotal in nephrogenesis, is quiescent in normal adult kidney and then reactivated in chronic kidney disease. First identified in in vitro models of $\mathrm{DN}$, there is now increasing evidence that gremlin is reactivated in and modulates TIF per se, possibly downstream of TGF- $\beta$. Gremlin is a BMP antagonist and thus characterization of its interactions with these molecules in the tubulointerstitial compartment is of great significance. An increased understanding of BMP-7 and other endogenous antagonists of EMT has resulted in in vivo models of CKD that demonstrate renal recovery when these agents are administered. Future work delineating the BMP-gremlin axis in modulation of epithelial cell plasticity may result in pharmacologic strategies which achieve reversal of human chronic renal fibrosis.

\section{Acknowledgements}

We thank Dr. Yvonne O' Meara for support and guidance. S.A.R. is funded by a clinical research fellowship from the Health Research Board of Ireland. D.P.B. is supported by a programme grant from the Health Research Board of Ireland. The Conway Institute is funded by the Programme for Research in Third Level Institutions in Ireland, administered by the Higher Education Authority (HEA). 


\section{References}

1 Schena F: Epidemiology of end stage renal disease: international comparisons of renal replacement therapy. Kidney Int 2000;57(suppl 74):S39-S45.

2 US Renal Data System, USRDS 2004 Annual Data Report: Atlas of End-Stage Renal Disease in the United States. www.usrds.org/adr_2004. htm.

$\checkmark 3$ Nath KA: The tubulointerstitium in progressive renal disease. Kidney Int 1998;54:992994.

4 Liu Y: Epithelial to mesenchymal transition in renal fibrogenesis: pathologic significance, molecular mechanism, and therapeutic intervention. J Am Soc Nephrol 2004; 15:1-12.

$\checkmark 5$ Zeisberg M, Kalluri R: The role of epithelialto-mesenchymal transition in renal fibrosis. J Mol Med 2004;82:175-181.

-6 Okada H, Inoue T, Suzuki H, Strutz F, Neilson EG: Epithelial-mesenchymal transformation of renal tubular epithelial cells in vitro and in vivo. Nephrol Dial Transplant 2000;15(suppl 6):44-46.

7 Fogo AB: Diabetic nephropathy: it's in the numbers. Kidney Int 2002;61:2274-2275.

$\checkmark 8$ Pedagogos E, Hewitson T, Fraser I, Nicholls K, Becker G: Myofibroblasts and arteriolar sclerosis in human diabetic nephropathy. Am J Kidney Dis 1997;29:912-918.

-9 Strutz F, Okada H, Lo CW, Danoff T, Carone RL, Tomaszewski JE, Neilson EG: Identification and characterization of a fibroblast marker: FSP-1. J Cell Biol 1995;130:393-405.

$\checkmark 10$ Horster MF, Braun GS, Huber SM: Embryonic renal epithelia: induction, nephrogenesis, and cell differentiation. Physiol Rev 1999;79: 1157-1191.

11 Valdes F, Alvarez AM, Locascio A, Vega S, Herrera B, Fernandez M, Benito M, Nieto MA, Fabregat I: The epithelial mesenchymal transition confers resistance to the apoptotic effects of transforming growth factor-beta in fetal rat hepatocytes. Mol Cancer Res 2002;1:68-78.

-12 Zeisberg M, Hanai J, Sugimoto H, Mammoto T, Charytan D, Strutz F, Kalluri R: BMP-7 counteracts TGF-beta1-induced epithelial-tomesenchymal transition and reverses chronic renal injury. Nat Med 2003;9:964-968.

- 13 Ng YY, Fan JM, Mu W, Nikolic-Paterson DJ, Yang WC, Huang TP, Atkins RC, Lan HY: Glomerular epithelial-myofibroblast transdifferentiation in the evolution of glomerular crescent formation. Nephrol Dial Transplant 1999; 14:2860-2872.

14 Yang J, Liu Y: Blockage of tubular epithelial to myofibroblast transition by hepatocyte growth factor prevents renal interstitial fibrosis. J Am Soc Nephrol 2002;13:96-107.

15 Okada H, Danoff TM, Kalluri R, Neilson EG: Early role of FSP-1 in epithelial-mesenchymal transformation. Am J Physiol 1997;273:F563F574.
16 Okada H, Ban S, Nagao S, Takahashi H, Suzuki H, Neilson EG: Progressive renal fibrosis in murine polycystic kidney disease: an immunohistochemical observation. Kidney Int 2000;58:587-597.

17 Okada H, Inoue T, Kanno Y, Kobayashi T, Ban S, Kalluri R, Suzuki H: Renal fibroblastlike cells in Goodpasture syndrome rats. Kidney Int 2001;60:597-606.

18 Ng YY, Huang TP, Yang WC, Chen ZP, Yang $\mathrm{AH}, \mathrm{Mu} \mathrm{W}$, Nikolic-Paterson DJ, Atkins RC, Lan HY: Tubular epithelial-myofibroblast transdifferentiation in progressive tubulointerstitial fibrosis in 5/6 nephrectomized rats. Kidney Int 1998;54:864-876.

19 Rastaldi MP, Ferrario F, Giardino L, Dell'Antonio G, Grillo C, Grillo P, Strutz F, Muller GA, Colasanti G, D'Amico G: Epithelial-mesenchymal transition of tubular epithelial cells in human renal biopsies. Kidney Int 2002;62:137-146.

20 Oldfield MD, Bach LA, Forbes JM, NikolicPaterson D, McRobert A, Thallas V, Atkins RC, Osicka T, Jerums G, Cooper ME: Advanced glycation end products cause epithelial-myofibroblast transdifferentiation via the receptor for advanced glycation end products (RAGE). J Clin Invest 2001;108:1853-1863.

-21 Iwano M, Plieth D, Danoff TM, Xue C, Okada H, Neilson EG: Evidence that fibroblasts derive from epithelium during tissue fibrosis. $\mathrm{J}$ Clin Invest 2002;110:341-350.

22 Yang J, Shultz RW, Mars WM, Wegner RE, Li Y, Dai C, Nejak K, Liu Y: Disruption of tissuetype plasminogen activator gene in mice reduces renal interstitial fibrosis in obstructive nephropathy. J Clin Invest 2002;110:15251538.

23 Yang J, Liu Y: Dissection of key events in tubular epithelial to myofibroblast transition and its implications in renal interstitial fibrosis. Am J Pathol 2001;159:1465-1475.

24 Fan JM, Ng YY, Hill PA, Nikolic-Paterson DJ, $\mathrm{Mu}$ W, Atkins RC, Lan HY: Transforming growth factor-beta regulates tubular epithelialmyofibroblast transdifferentiation in vitro. Kidney Int 1999;56:1455-1467.

25 Gore-Hyer E, Shegogue D, Markiewicz M, Lo S, Hazen-Martin D, Greene EL, Grotendorst G, Trojanowska M: TGF-beta and CTGF have overlapping and distinct fibrogenic effects on human renal cells. Am J Physiol Renal Physiol 2002;283:F707-F716.

26 Strutz F, Zeisberg M, Ziyadeh FN, Yang CQ, Kalluri R, Muller GA, Neilson EG: Role of basic fibroblast growth factor-2 in epithelial-mesenchymal transformation. Kidney Int 2002; 61:1714-1728.

27 Yang J, Dai C, Liu Y: Hepatocyte growth factor gene therapy and angiotensin II blockade synergistically attenuate renal interstitial fibrosis in mice. J Am Soc Nephrol 2002;13:24642477.
28 Fan JM, Huang XR, Ng YY, Nikolic-Paterson DJ, Mu W, Atkins RC, Lan HY: Interleukin-1 induces tubular epithelial-myofibroblast transdifferentiation through a transforming growth factor-beta1-dependent mechanism in vitro. Am J Kidney Dis 2001;37:820-831.

29 Cheng S, Lovett DH: Gelatinase A (MMP-2) is necessary and sufficient for renal tubular cell epithelial-mesenchymal transformation. Am J Pathol 2003;162:1937-1949.

30 Bhowmick NA, Zent R, Ghiassi M, McDonnell M, Moses HL: Integrin-beta1 signaling is necessary for transforming growth factor-beta activation of p38MAPK and epithelial plasticity. J Biol Chem 2001;276:46707-46713.

31 Bhowmick NA, Ghiassi M, Bakin A, Aakre M, Lundquist CA, Engel ME, Arteaga CL, Moses HL: Transforming growth factor-betal mediates epithelial to mesenchymal transdifferentiation through a RhoA-dependent mechanism. Mol Biol Cell 2001;12:27-36.

32 Hartsough MT, Mulder KM: Transforming growth factor beta activation of p44MAPK in proliferating cultures of epithelial cells. J Biol Chem 1995;270:7117-7124.

33 Zavadil J, Bitzer M, Liang D, Yang YC, Massimi A, Kneitz S, Piek E, Bottinger EP: Genetic programs of epithelial cell plasticity directed by transforming growth factor-beta. Proc Natl Acad Sci USA 2001;98:6686-6691.

>34 Hocevar BA, Brown TL, Howe PH: TGF-beta induces fibronectin synthesis through a c-Jun N-terminal kinase-dependent, Smad4-independent pathway. Embo J 1999; 18:13451356.

35 Rhyu DY, Yang Y, Ha H, Lee GT, Song JS, Uh ST, Lee HB: Role of reactive oxygen species in TGF-beta1-induced mitogen-activated protein kinase activation and epithelial-mesenchymal transition in renal tubular epithelial cells. J Am Soc Nephrol 2005;16:667-675.

>36 Sadlier DM, Connolly SB, Kieran NE, Roxburgh S, Brazil DP, Kairaitis L, Wang Y, Harris DC, Doran P, Brady HR: Sequential extracellular matrix-focused and baited-global cluster analysis of serial transcriptomic profiles identifies candidate modulators of renal tubulointerstitial fibrosis in murine adriamycin-induced nephropathy. J Biol Chem 2004;279: 29670-29680.

37 Dudley AT, Lyons KM, Robertson EJ: A requirement for bone morphogenetic protein-7 during development of the mammalian kidney and eye. Genes Dev 1995;9:2795-2807.

38 Miyazaki Y, Oshima K, Fogo A, Hogan BL, Ichikawa I: Bone morphogenetic protein-4 regulates the budding site and elongation of the mouse ureter. J Clin Invest 2000;105:863873.

39 Piscione TD, Yager TD, Gupta IR, Grinfeld B, Pei Y, Attisano L, Wrana JL, Rosenblum ND: BMP-2 and OP-1 exert direct and opposite effects on renal branching morphogenesis. Am J Physiol 1997;273:F961-F975. 
40 Simon M, Maresh JG, Harris SE, Hernandez JD, Arar M, Olson MS, Abboud HE: Expression of bone morphogenetic protein-7 mRNA in normal and ischemic adult rat kidney. Am J Physiol 1999;276:F382-F389.

41 Wang SN, Lapage J, Hirschberg R: Loss of tubular bone morphogenetic protein-7 in diabetic nephropathy. J Am Soc Nephrol 2001;12: 2392-2399.

42 Zeisberg M, Bottiglio C, Kumar N, Maeshima Y, Strutz F, Muller GA, Kalluri R: Bone morphogenic protein-7 inhibits progression of chronic renal fibrosis associated with two genetic mouse models. Am J Physiol Renal Physiol 2003;285:F1060-F1067.

- 43 Wang S, Chen Q, Simon TC, Strebeck F, Chaudhary L, Morrissey J, Liapis H, Klahr S, Hruska KA: Bone morphogenic protein-7 (BMP-7), a novel therapy for diabetic nephropathy. Kidney Int 2003;63:2037-2049.

44 Morrissey J, Hruska K, Guo G, Wang S, Chen Q, Klahr S: Bone morphogenetic protein-7 improves renal fibrosis and accelerates the return of renal function. J Am Soc Nephrol 2002; 13(suppl 1):S14-S21.

45 Gould SE, Day M, Jones SS, Dorai H: BMP-7 regulates chemokine, cytokine, and hemodynamic gene expression in proximal tubule cells. Kidney Int 2002;61:51-60.

46 Wang S, Hirschberg R: BMP-7 antagonizes TGF-beta-dependent fibrogenesis in mesangial cells. Am J Physiol Renal Physiol 2003; 284:F1006-F1013.

- 47 Zeisberg M, Shah AA, Kalluri R: Bone morphogenic protein-7 induces mesenchymal to epithelial transition in adult renal fibroblasts and facilitates regeneration of injured kidney. J Biol Chem 2005;280:8094-8100.

-48 Zeisberg M, Muller GA, Kalluri R: Are there endogenous molecules that protect kidneys from injury? The case for bone morphogenic protein-7 (BMP-7). Nephrol Dial Transplant 2004; 19:759-761.

-49 Topol LZ, Bardot B, Zhang Q, Resau J, Huillard E, Marx M, Calothy G, Blair DG: Biosynthesis, post-translation modification, and functional characterization of Drm/Gremlin. J Biol Chem 2000;275:8785-8793.

-50 Lappin DW, McMahon R, Murphy M, Brady HR: Gremlin: an example of the re-emergence of developmental programmes in diabetic nephropathy. Nephrol Dial Transplant 2002; 17(suppl 9):65-67.
51 Merino R, Rodriguez-Leon J, Macias D, Ganan Y, Economides AN, Hurle JM: The BMP antagonist Gremlin regulates outgrowth, chondrogenesis and programmed cell death in the developing limb. Development 1999; 126: 5515-5522.

52 Hsu DR, Economides AN, Wang X, Eimon PM, Harland RM: The Xenopus dorsalizing factor Gremlin identifies a novel family of secreted proteins that antagonize BMP activities. Mol Cell 1998;1:673-683.

53 Topol LZ, Marx M, Laugier D, Bogdanova NN, Boubnov NV, Clausen PA, Calothy G, Blair DG: Identification of drm, a novel gene whose expression is suppressed in transformed cells and which can inhibit growth of normal but not transformed cells in culture. Mol Cell Biol 1997; 17:4801-4810.

54 Khokha MK, Hsu D, Brunet LJ, Dionne MS, Harland RM: Gremlin is the BMP antagonist required for maintenance of Shh and Fgf signals during limb patterning. Nat Genet 2003; 34:303-307.

55 Michos O, Panman L, Vintersten K, Beier K, Zeller R, Zuniga A: Gremlin-mediated BMP antagonism induces the epithelial-mesenchymal feedback signaling controlling metanephric kidney and limb organogenesis. Development 2004;131:3401-3410.

-56 Murphy M, Godson C, Cannon S, Kato S, Mackenzie HS, Martin F, Brady HR: Suppression subtractive hybridization identifies high glucose levels as a stimulus for expression of connective tissue growth factor and other genes in human mesangial cells. J Biol Chem 1999; 274:5830-5834.

57 McMahon R, Murphy M, Clarkson M, Taal M, Mackenzie HS, Godson C, Martin F, Brady HR: IHG-2, a mesangial cell gene induced by high glucose, is human gremlin. Regulation by extracellular glucose concentration, cyclic mechanical strain, and transforming growth factor-beta1. J Biol Chem 2000;275:9901-9904.

58 Kattla J, Harno E, Dorman A, Brady H, Godson C, Brazil D: Identification of Connective Tissue Growth Factor as a potential early marker of Diabetic Nephropathy in the GotoKakizaki rat model of type 2 diabetes (abstract). J Am Soc Nephrol 2004; 15:264A.

59 Murphy M, McMahon R, Clarkson M, Gupta S, Brady HR: Induction of gremlin expression in the remnant kidney in vivo and during TGFbeta-induced epithelial-mesenchymal transformation in vitro (abstract). J Am Soc Nephrol 2000;11:625A.
60 Dolan V, Murphy M, Sadlier D, Lappin D, Doran P, Godson C, Martin F, O'Meara Y, Schmid H, Henger A, Kretzler M, Droguett A, Mezzano S, Brady HR: Expression of gremlin, a bone morphogenetic protein antagonist, in human diabetic nephropathy. Am J Kidney Dis 2005;45:1034-1039.

61 Neilson EG: Setting a trap for tissue fibrosis. Nat Med 2005;11:373-374.

62 Abreu JG, Ketpura NI, Reversade B, De Robertis EM: Connective-tissue growth factor (CTGF) modulates cell signalling by BMP and TGF-beta. Nat Cell Biol 2002;4:599-604.

63 Roxburgh S, Kattla J, Sadlier D, O’Meara Y, Pollock C, Brazil D: Differential expression of actin cytoskeletal genes during epithelial-tomesenchymal transition (abstract). Nephrology 2005; 10:A396.

64 Lin J, Patel SR, Cheng X, Cho EA, Levitan I, Ullenbruch M, Phan SH, Park JM, Dressler GR: Kielin/chordin-like protein, a novel enhancer of BMP signaling, attenuates renal fibrotic disease. Nat Med 2005;11:387-393.

65 Wu C, Dedhar S: Integrin-linked kinase (ILK) and its interactors: a new paradigm for the coupling of extracellular matrix to actin cytoskeleton and signaling complexes. J Cell Biol 2001; 155:505-510

66 Ozdamar B, Bose R, Barrios-Rodiles M, Wang HR, Zhang Y, Wrana JL: Regulation of the polarity protein Par- 6 by TGF-beta receptors controls epithelial cell plasticity. Science 2005; 307:1603-1609.

67 Nagatoya K, Moriyama T, Kawada N, Takeji M, Oseto S, Murozono T, Ando A, Imai E, Hori M: Y-27632 prevents tubulointerstitial fibrosis in mouse kidneys with unilateral ureteral obstruction. Kidney Int 2002;61:1684-1695.

68 Li JH, Wang W, Huang XR, Oldfield M, Schmidt AM, Cooper ME, Lan HY: Advanced glycation end products induce tubular epithelial-myofibroblast transition through the RAGE-ERK1/2 MAP kinase signaling pathway. Am J Pathol 2004;164:1389-1397.

69 Strutz F, Heeg M, Kochsiek T, Siemers G, Zeisberg M, Muller GA: Effects of pentoxifylline, pentifylline and gamma-interferon on proliferation, differentiation, and matrix synthesis of human renal fibroblasts. Nephrol Dial Transplant 2000;15:1535-1546.

70 Liu Y, Rajur K, Tolbert E, Dworkin LD: Endogenous hepatocyte growth factor ameliorates chronic renal injury by activating matrix degradation pathways. Kidney Int 2000;58: 2028-2043. 